\title{
Cost in perspective: direct assessment of American market acceptability of Co-60 in gynecologic high-dose-rate brachytherapy and contrast with experience abroad
}

\author{
Raymond B. Mailhot Vega, MD, MPH',2, David Barbee, PhD!' Wesley Talcott, MD, MBA³, Tamara Duckworth, MS' \\ Bhartesh A. Shah, MD!, Omar F. Ishaq, MD, Christina Small, MPH', Anamaria R. Yeung, MD6 , Carmen A. Perez, MD, PhD!, \\ Peter B. Schiff, MD, PhD!, Ophira Ginsburg, MD!, William Small, Jr, MD5, May Abdel-Wahab, MD, PhD? \\ Gustavo Sarria Bardales, MD , Matthew Harkenrider, MD6 \\ 'Department of Radiation Oncology, NYU School of Medicine New York, New York, USA, ${ }^{2}$ Department of Radiation Oncology, University of \\ Florida College of Medicine, Jacksonville, FL, USA, 3 Department of Radiation Oncology, Yale University School of Medicine New Haven, CT, \\ USA, ${ }^{4}$ Department of Radiation Oncology, W Temple Webber Cancer Center, Texarkana, Texas, USA, ${ }^{5}$ Department of Radiation Oncology. \\ Stritch School of Medicine, Loyola University Chicago, Chicago, IL, USA, 'Department of Radiation Oncology, University of Florida College \\ of Medicine, Gainesville, FL, USA, ${ }^{7}$ Division of Human Health, International Atomic Energy Agency, Vienna, Austria, ${ }^{8}$ Instituto Nacional de \\ Enfermedades Neoplásicas, Department of Radiation Oncology, Surquillo, Peru
}

\begin{abstract}
Purpose: While Ir-192 remains the mainstay isotope for gynecologic high-dose-rate (HDR) brachytherapy in the U.S., Co-60 is used abroad. Co-60 has a longer half-life than Ir-192, which may lead to long-term cost savings; however, its higher energy requires greater shielding. This study analyzes Co-60 acceptability based on a one-time expense of additional shielding and reports the financial experience of Co-60 in Peru's National Cancer Institute, which uses both isotopes.

Material and methods: A nationwide survey was undertaken assessing physician knowledge of Co-60 and willingness-to-pay (WTP) for additional shielding, assuming a source more cost-effective than Ir-192 was available. With 440 respondents, 280 clinicians were decision-makers and provided WTPs, with results previously reported. After completing a shielding report, we estimated costs for shielding expansion, noting acceptability to decision makers' WTP. Using activity-based costing, we note the Peruvian fiscal experience.

Results: Shielding estimates ranged from $\$ 173,000$ to $\$ 418,000$. The percentage of respondents accepting high-density modular or lead shielding (for union and non-union settings) were $17.5 \%, 11.4 \%$, 3.9\%, and 3.2\%, respectively. Shielding acceptance was associated with greater number of radiation oncologists in a respondent's department but not time in practice or the American Brachytherapy Society membership. Peru's experience noted cost savings with Co-60 of $\$ 52,400$ annually.

Conclusions: By comparing the cost of additional shielding for a sample institution's HDR suite with radiation oncologists' WTP, this multi-institutional collaboration noted $<20 \%$ of clinicians would accept additional shielding. Despite low acceptability in the US, Co-60 demonstrates cost-favorability in Peru and may similarly in other locations.

Key words: brachytherapy, cobalt-60, costs and cost analysis, economics, decision-making, gynecologic tumor, HDR, survey.

\section{Purpose}

Brachytherapy represents the oldest form of therapeutic radiation oncology [1]. From the initial implementation of radium, it was noted that gynecological cancers would respond clinically to radiotherapy [2]. Subsequent developments actually led to the use of Co-60 as a lowdose-rate (LDR) implant for interstitial needles and wires that by the 1960s, gave way to more commonly employed Cs-137 [3,4,5]. The development and rapid uptake of

Address for correspondence: Raymond B. Mailhot Vega, MD, MPH, Department of Radiation Oncology, Received: 04.09.2018 University of Florida Proton Therapy Institute, University of Florida, 2015 North Jefferson Street, Jacksonville, Accepted: 03.11 .2018 FL 32206, USA, phone: +1 904588 1800, fax: +1 904588 1300, e-mail: rbmailhot@floridaproton.org Published: 28.12 .2018 
high-dose-rate (HDR) afterloader-based brachytherapy came about due to the usage of Ir-192, owing to its miniaturization and high specific activity, which has increased usage in gynecologic brachytherapy in the United States $[6,7,8]$. While radiobiological differences have yet to determine an oncologically more favorable isotope $[9,10,11]$, the clear benefits of remote afterloader HDR for gynecological cancer management include the reduction of dose exposure to health care workers and generally quicker treatment times for patients [12].

Today, Ir-192 represents the mainstay of brachytherapy - dominating HDR brachytherapy - in the American market, but Co-60 did have a short stint in manual HDR brachytherapy in the 1960s $[4,13]$. With its shorter halflife compared to the aforementioned isotopes, Ir-192 requires an increased number of source exchanges. These frequent source exchanges place a greater demand on human capital by requiring physicist time and can disrupt clinical schedules for the necessary downtime. Additionally, such frequent source exchanges make Ir-192 a resource-intensive isotope for low- to middle-income countries. Recently, Co-60 was miniaturized and made available abroad as an HDR isotope in many locales worldwide, including Spain, Germany, Austria, Peru, and Nigeria $[14,15,16,17,18]$. Despite the significant advantage of Co-60's longer half-life of 5 years compared to Ir-192's, it is counterbalanced by the additional shielding requirement due to its higher energy.

Dosimetric comparisons show that no clinical differences are expected between the two isotopes $[19,20]$. In clinical situations comparing two different treatments, cost-effectiveness analyses represent a methodology for determining a more favorable strategy. When clinical outcomes are not expected to vary, such an analysis is reduced to a cost comparison. We have previously reported on the willingness-to-pay (WTP) of self-described clinical decision-makers for a theoretically more cost-effective isotope compared to Ir-192 [21]. As Ir-192 has become the mainstay of HDR brachytherapy treatment for gynecological malignancies in the U.S., facilities that wish to switch to Co-60 may be faced with a one-time expense for increasing shielding. In this study, we sought to determine the market acceptability of Co-60 by using directly-assessed WTP values and comparing them with pricing quotes from shielding vendors to reflect the costs associated with increased shielding at a single institution.

\section{Material and methods}

The goal of this work was to evaluate the market acceptability of Co-60 in the American market as an isotope for HDR brachytherapy in the management of gynecological cancers. In addition, we wanted to complete cost comparisons in another market, which had both Ir-192 and Co-60, and we partnered with the National Cancer Institute of Peru (INEN) to complete that evaluation.

\section{American market acceptability}

To first assess market acceptability, we determined the WTP of radiation oncology decision-makers. This methodology has been published previously but briefly, we conducted a nationwide survey of radiation oncologists (both residents and those post-residency), and assessed survey participant demographics, their knowledge of HDR sources, brachytherapy unit shielding, factors that may influence source-selection, and their WTP for a source more cost-effective than Ir-192. This allowed for direct determination of WTP. Comparative statistics evaluated the association between demographic characteristics of respondents and WTP selection. Analyses of categorical data were conducted using chi-square and Fisher's exact test on SPSS. The survey questions are presented in Appendix 1 (published as supplementary data in electronic form) [21].

Secondly, we selected a sample facility, for which Co60 installation would require additional shielding owing to its higher energy compared to Ir-192. The facility is an academic institution, with a dedicated HDR suite within a hospital used for brachytherapy treatment. Details and specifications for the suite are in Appendix 2 (published as supplementary data in electronic form). Once selected, we completed a shielding report to determine the tenth-value-layers (TVLs) necessary to maintain consistently appropriate safety standards. The workload calculations were performed with the following assumptions: $10 \mathrm{Ci}$, Ir-192 source, 10 patients per day, 10-minute treatment duration per patient, for a total treatment time of $8.33 \mathrm{hr} / \mathrm{wk}$. This results in a workload of $38.4 \mathrm{cGy} / \mathrm{wk}$ at 1 meter and has been seen to be an overestimate during the first 18 months of HDR operation. Maximum permissible doses for all areas were calculated for a maximum exposure rate of $0.02 \mathrm{mSv} / \mathrm{wk}$ (2 mrem/wk or $1 \mathrm{mSv} / \mathrm{yr})$ and $0.02 \mathrm{mSv}$ (2 mrem) in any hour [22,23]. Report \#49 of the National Council on Radiation Protection and Measurements (NCRP) was used to calculate barrier thicknesses required to achieve the necessary exposure rate at seven locations for controlled and non-controlled areas, with varying occupancy [24]. Barriers assessed include the door, walls, ceiling, floor, and ducts.

To estimate the cost required for the calculated additional shielding, we reached out to both external vendors as well as the institutional internal contractor to provide quotes for this theoretical expansion. One vendor was able to complete the price quotes, detailing the cost of shielding for two different types of shielding material (lead and a proprietary high-density modular shielding) for both union and non-union labor settings. Four different cost levels reflecting quotes for proprietary shielding and lead for both labor scenarios were calculated. Costs are presented in 2018 U.S. dollars (USD).

With direct ascertainment of decision-maker WTP and price quotes for shielding expansion, we then determined the percentage of respondents who would accept the one-time shielding cost per the obtained price quotes. Comparative statistics were completed using the four different cost thresholds with respondent WTP across different demographic strata to identify any significant differences in cost-acceptance. These categorical tests (chi-square and Fisher's exact test) were completed in SPSS (Armonk, NY, USA). For categorical tests, in which 
tables larger than $2 \times 2$ were constructed and minimum expected cell values were less than five, likelihood ratio tests were used instead.

\section{Peruvian experience}

INEN currently has afterloaders operational for treatments with both Ir-192 and Co-60. INEN has a national catchment for the country of Peru, with their Department of Radiotherapy seeing approximately 5,200 patients per year and 900 patients undergoing gynecological brachytherapy [25]. By partnering and reviewing their fiscal experience, we evaluated the cost differences between the two HDR isotopes for this national cancer center. INEN prepared a budget using an activity-based costing framework to assess any differences in costs that may arise owing to the different sources $[26,27]$. In such a strategy, patients were tracked throughout the gynecological brachytherapy experience to estimate the costs incurred along their path with expenses including personnel, equipment and furniture, equipment depreciation, supplies, medication, and services. Costs are presented in the Peruvian currency of Nuevo Soles and converted to 2018 USD. This budget is presented in English in Appendix 3 (published as supplementary data in electronic form).

\section{Results}

\section{Willingness-to-pay and factors associated with willingness to invest in a new HDR isotope}

Between June and July 2015, 509 surveys were initiated, and 440 surveys were completed. Of the 440 surveys, $268(64 \%)$ identified as being involved in radiotherapy equipment selection. A histogram of the WTP responses provided by these self-identified decision-makers is presented in Figure 1 [21]. Physicians' most common selection for WTP was less than $\$ 25,000$.

Demographic and facility information provided by the respondents was evaluated alongside respondents'

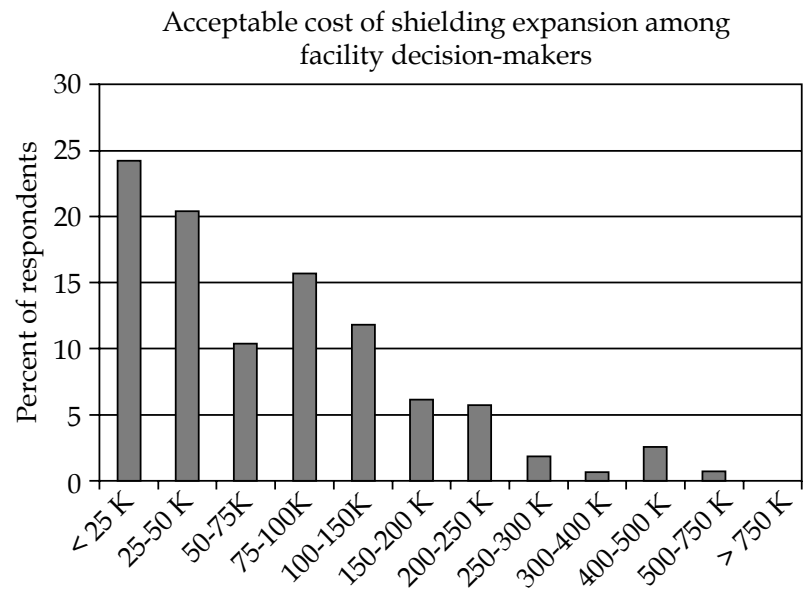

Acceptable cost of shielding (USD)

Fig. 1. Histogram of WTP answers: Histogram of WTP breakdowns, which survey respondents were willing to accept for one-time shielding cost. WTP = willingness-to-pay answers for WTP. The results of comparative testing with $p$-values most approaching significance are presented in Table 1. The majority of those self-identified decision-makers were more than ten years post-residency. Notably, the single answer associated with selected WTP was the number of attending radiation oncologists in a respondent's department $(p=0.013)$; respondents in facilities with higher number of attendings were likely to select increased WTP values.

Other covariates examined that were not significantly associated with WTP include a center's performing HDR brachytherapy for gynecologic cancer $(p=0.63)$, involvement in HDR brachytherapy planning for gynecologic tumor management $(p=0.99)$, number of afterloaders at a facility $(p=0.60)$, and the number of practitioners at a center who perform brachytherapy $(p=0.77)$.

Table 1. Demographic information

\begin{tabular}{lcc} 
& $N(\%)$ & $P$-value \\
\hline What is your level of training? & & \\
\hline Residency & $5(1.8)$ & 0.34 \\
\hline Post-residency, < 5 years & $48(17.1)$ & \\
\hline Post-residency, 5-10 years & $53(18.9)$ & \\
\hline Post-residency, 10+ years & $174(62.1)$ & \\
\hline Are you a member of ABS? & & \\
\hline Yes & $122(43.6)$ & 0.085 \\
\hline No & $158(56.4)$ &
\end{tabular}

In the past year, have you attended any national conferences specific for brachytherapy?

\begin{tabular}{lcl}
\hline Yes & $62(22.1)$ & 0.078 \\
\hline No & $218(77.9)$ &
\end{tabular}

In the past year, have you attended any sponsored events with vendors of brachytherapy equipment?

\begin{tabular}{lcl}
\hline Yes & $56(20.0)$ & 0.15 \\
\hline No & $224(80.0)$ &
\end{tabular}

Could the respondent name Co-60 as an isotope available for HDR brachytherapy?

\begin{tabular}{lcl}
\hline Yes & $60(21.4)$ & 0.38 \\
\hline No & $220(78.6)$ &
\end{tabular}

Approximately, how many of your attending radiation oncologists are in your department?

\begin{tabular}{|c|c|}
\hline $1-5$ & $178(63.6)$ \\
\hline $6-10$ & $62(22.1)$ \\
\hline $11-15$ & $22(7.9)$ \\
\hline $16-20$ & $10(3.6)$ \\
\hline $21-25$ & $6(2.1)$ \\
\hline$\geq 26$ & $2(0.7)$ \\
\hline
\end{tabular}

${ }^{*} p<0.05$ 


\section{Shielding report and cost analysis}

After selecting a sample institution with an HDR brachytherapy suite currently shielded for Ir-192, a shielding report was completed to assess the additional TVLs necessary to account for the shielding deficit created when changing radioactive isotope from Ir-192 to the higher energy Co-60 of a similar workload. The dimensions of the suite are $15^{\prime}$ wide, $12^{\prime} 5^{\prime \prime}$ deep, and $10^{\prime} 6^{\prime \prime}$ high. The complete shielding report is presented in Appendix 2. To maintain the same level of shielding for the aforementioned specifications, the following TVLs are needed: 1.11 for walls, 2.46 for the door, and 1.15 for both ceiling and floor. In collaboration with an external vendor, prices were calculated for the additional shielding using proprietary commercial shielding as well as lead for both union and non-union settings. The budgetary items accounting for design, shielding, the door, shipping, and installation are presented in Table 2 in addition to the total cost.

The cost quotes range in price from $\$ 173,500$ to $\$ 418,000$. With regards to pricing, union settings were associated with higher costs for shipping and installation. Costs associated with lead shielding were higher than those for the proprietary shielding. For the proprietary shielding, the majority of the cost was associated with the shielding needed for the door for the HDR suite; this contrasts with the higher costs for lead shielding, for which the shielding itself accounted for the majority of the cost. For both cases, shipping accounted for less than ten percent of the total cost, but shielding quotes noted an approximate doubling in the cost of shipping and installation for union settings. Based on the material selected, the type of labor employed raised costs approximately ten to twenty percent.

Table 2. Shielding costs

Proprietary custom shielding

\begin{tabular}{lcc}
\hline Description & Non-union (\%) & Union (\%) \\
\hline Design & $\$ 16,000(9.2)$ & $\$ 16,000(7.6)$ \\
\hline Shielding (proprietary) & $\$ 40,000(23.1)$ & $\$ 40,000(19.0)$ \\
\hline Custom door & $\$ 80,000(46.1)$ & $\$ 80,000(37.9)$ \\
\hline Shipping & $\$ 7,500(4.3)$ & $\$ 15,000(7.1)$ \\
\hline Install & $\$ 30,000(17.3)$ & $\$ 60,000(28.4)$ \\
\hline Total & $\$ 173,500.00$ & $\$ 211,000.00$ \\
\hline Lead shielding & & \\
\hline Description & $\$ 16,000(4.2)$ & $\$ 16,000(3.8)$ \\
\hline Design & $\$ 220,000(58.4)$ & $\$ 220,000(52.6)$ \\
\hline Shielding (lead) & $\$ 100,000(26.6)$ & $\$ 100,000(23.9)$ \\
\hline Custom door & $\$ 5,500(1.5)$ & $\$ 12,000(2.9)$ \\
\hline Shipping & $\$ 35,000(9.3)$ & $\$ 70,000(16.7)$ \\
\hline Install & $\$ 376,500.00$ & $\$ 418,000.00$ \\
\hline Total & & \\
\hline
\end{tabular}

With the available price quotes and previously directly obtained WTP selections from survey participants, we noted for different cost scenarios, what percentage of respondents would have accepted the additional shielding; acceptability is captured in Table 3. Apart from the least costly quote for non-labor provided proprietary shielding, no residents were willing to invest in any of the three more expensive quotes. Self-identified decision-makers who had attended a national brachytherapy conference in the last year were significantly more likely to pay for the proprietary shielding than those who had not attended (non-union: $p=0.001$; union: $p=0.026$ ). And similar to the finding from Table 1, number of attending radiation on-

Table 3. Acceptability of shielding per respondent WTP

\begin{tabular}{lcccc} 
& \multicolumn{4}{c}{$\begin{array}{c}\text { Percentage of respondents } \\
\text { accepting this cost }\end{array}$} \\
\cline { 2 - 5 } & $\begin{array}{c}\text { Proprietary } \\
\text { shielding }\end{array}$ & Lead shielding \\
\hline Respondents group (\%) & $\begin{array}{c}\text { Non- } \\
\text { union }\end{array}$ & Union & $\begin{array}{c}\text { Non- } \\
\text { union }\end{array}$ & Union \\
\hline All respondents (100) & 17.5 & 11.4 & 3.9 & 3.2 \\
\hline What is your level of training? & & & \\
\hline Residency (1.8) & 40.0 & 0.0 & 0.0 & 0.0 \\
\hline $\begin{array}{l}\text { Post-residency, } \\
\text { < 5 years (17.1) }\end{array}$ & 10.4 & 6.3 & 2.1 & 2.1 \\
\hline $\begin{array}{l}\text { Post-residency, } \\
\text { 5-10 years (18.9) }\end{array}$ & 20.8 & 15.1 & 3.8 & 3.8 \\
\hline $\begin{array}{l}\text { Post-residency, } \\
\text { 10+ years (62.1) }\end{array}$ & 17.8 & 12.1 & 4.6 & 3.4 \\
\hline ABS membership & & & & \\
\hline Yes (43.6) & 18.0 & 9.0 & 2.4 & 1.6 \\
\hline No (56.4) & 17.1 & 13.3 & 5.1 & 4.4 \\
\hline
\end{tabular}

Attendance of a national brachytherapy conference in the past year

\begin{tabular}{lcccc}
\hline Yes (22.1) & $32.3^{\star}$ & $19.4^{\star}$ & 8.1 & 6.5 \\
\hline No (77.9) & 13.3 & 9.2 & 2.8 & 2.3 \\
\hline
\end{tabular}

Attendance of a sponsored event with vendor of brachytherapy equipment in the past year

\begin{tabular}{lcccc}
\hline Yes (20.0) & $26.8^{*}$ & 14.3 & 7.1 & 5.4 \\
\hline No (80.0) & 15.2 & 10.7 & 3.1 & 2.7 \\
\hline
\end{tabular}

Approximately, how many attending radiation oncologists are in your department?

\begin{tabular}{lcccc}
\hline $1-5(63.6)$ & $13.5^{\star}$ & 9.0 & $2.8^{\star}$ & 2.2 \\
\hline $6-10(22.1)$ & 19.4 & 11.3 & 3.2 & 3.2 \\
\hline $11-15(7.9)$ & 18.2 & 18.2 & 0.0 & 0.0 \\
\hline $15-20(3.6)$ & 50.0 & 30.0 & 20.0 & 10.0 \\
\hline $20-25(2.1)$ & 50.0 & 16.7 & 16.7 & 16.7 \\
\hline$\geq 26(0.7)$ & 50.0 & 50.0 & 50.0 & 50.0
\end{tabular}

*Statistical significance between groups. 
cologists was significantly associated with respondent's WTP for non-union shielding increase (proprietary modular shielding: $p=0.033$; lead: $p=0.045$ ).

\section{Peruvian experience}

Using an activity-based micro-costing strategy following a brachytherapy patient, total costs estimated include 22 human resource activities, 24 distinct uses of equipment and furniture, 9 supply costs, and a partial brachytherapy suite cost. The cost analysis determined that Co-60 was less expensive than Ir-192. In particular, the cost of the source was cheaper with Co-60. Using Co-60 saved approximately 78 nuevo soles, equivalent to approximately $\$ 24.27$ for each treatment. INEN treats approximately 900 patients with gynecological cancer with brachytherapy and of these, $80 \%$ of patients are treated with two fractions and the rest in four fractions. With these clinical parameters treating with Co-60, yields an estimated cost savings of Co-60 annually of approximately $\$ 52,400$.

\section{Discussion}

Using WTP values directly obtained from radiation oncologists, we provide a market assessment for the acceptability of Co-60 for facilities in which shielding expansion would be required. Ir-192 has remained the predominant isotope used in the United States for HDR brachytherapy for gynecological malignancies, and the miniaturization of Co-60 represented a competitor in this market, with the advantage of a longer half-life. Interestingly, the timeline of first starting this current study corresponded with the FDA 510k approval of a Co-60 afterloader into the American market. Upon written completion of this study, the company has removed the product from the American market. In this way, this work somewhat reflects a post-mortem for its experience in the U.S. despite its continued use abroad.

The large sample size of respondents, from which this work is derived, is a definite strength. With 268 self-described decision-makers, there was enough power not only to assess WTP and assess acceptability for different pricing scenarios, but also complete hypothesis-generating subset analyses to attempt to explain what features may influence a respondent's WTP. The respondent pool was also diverse in its make-up. The majority of respondents had been in practice for more than ten years, and approximately one-half of those surveyed were members of the American Brachytherapy Society (ABS). To ascertain market acceptability, we completed an in-depth shielding report of a sample institution and obtained four different costing-scenario estimates. Most importantly, the WTPs with which we used to determine acceptability, were directly obtained from radiation oncologists and not modeled or obtained from secondary data sources.

There are several limitations to the work we present. While we are deeply grateful to our vendor in determining cost estimates for additional shielding at no cost, we were limited in our ability to obtain other fair-market quotes. Also, the costs presented reflect those needed for one single-institution. Given the urban location of that representative facility and the high-cost per square-foot, it is likely other estimates would in fact be lower. Another weakness in the work we present is that though the WTP is directly assessed from physicians, decision-making in radiation oncology is generally shared with physicist input. The e-mail listserv we used to query respondents did not include physicists. Given the complexities that occur within institutions regarding large capital purchases and facilities upgrades, there is no way to incorporate likelihood to have financial institutional support for required shielding.

It is safe to say that our field of radiation oncology has been critiqued for its high capital costs. For such a reputation, we were surprised to find such low WTP answers, which translated to low acceptability. Even in our least costly scenario, less than one-fifth of respondents would have accepted the cost of shielding expansion. In exploratory subset analyses, it was noted that respondents who worked in facilities with more radiation oncologists were comfortable with higher WTPs - perhaps since the higher number of employed physicians reflects higher budgets and expenditures. Similarly, the subset analyses noted that those respondents who had either attended a brachytherapy conference or met with a brachytherapy vendor within the last year were significantly more likely to accept the non-union proprietary shielding - such acceptance may reflect that those unfamiliar with source or shielding costs underestimated the cost of shielding. However, the ABS membership was not significantly associated with shielding acceptability for any of the four costing scenarios.

Despite the low acceptability of Co-60 in the U.S. markets, other investigators have posited a cost-benefit particularly in the developing world [15]. Its longer half-life necessitates fewer source exchanges, and less frequent source exchanges may be logistically preferable in resource-challenged health care systems as is frequent in low- and middle-income countries. The additional challenges of frequent source changes in low- and middle-income countries include additional budgetary, safety, administrative, and customs issues, which may lead to longer downtime and less use of the machine, affecting access to care. For example, in some settings, the difficulty of frequent purchasing of the sources every few months through a limited operating budget would be noted as compared to an upfront investment in more shielding and request of source change, an expensive item, once every few years. Safety issues during transportation can also be a challenge due to the frequent transport of the sources, as opposed to a heavily supervised single event every few years. As for customs, the short half-life of the Ir-192 would mean a disproportionate effect on dose rate with customs delays, which are not uncommon in many low- and middle-income countries. While disruption of service and greater use of physicists' time affects both low- and middle-income countries as well as high-income countries, it may have a disproportionate effect on low- and middle-income countries owing to higher patient loads per machine, limited machines, and relatively 
A

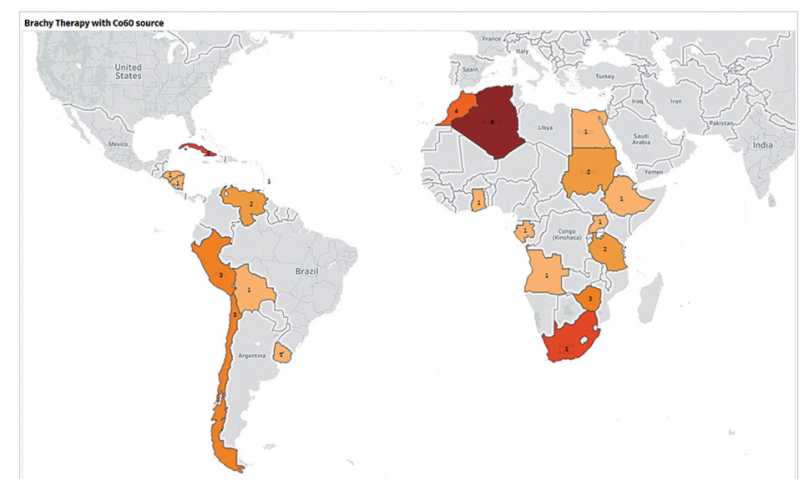

B

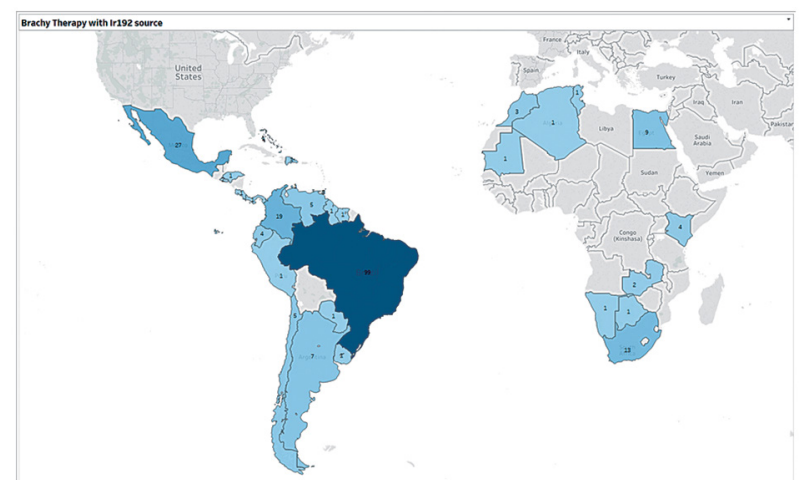

Fig. 2. Geographic representation of high-dose-rate afterloaders for Co-60 (A) and Ir-192 (B) for the Caribbean, Central and South America, and Africa

sparse human resources, especially medical physicists. Co-60 afterloaders would allow for greater access to care for patients in need of brachytherapy, with the cost savings and much less frequent necessary source exchanges. Partnering with INEN, we looked at Peru's own experience using an activity-based costing approach with their budget. The approach taken to evaluate costs was exhaustive and comprehensive, and noted cost-favorability with Co-60. In absence of any demonstrable clinical difference between the two isotopes, Co- 60 may be preferable from a financial standpoint - such preference in other locations must also consider the radiation safety needed for storing an isotope with a longer half-life. Figure 2 displays the current utilization of Ir-192 and Co-60 in the Caribbean, Central and South America, and Africa; currently, the number of afterloaders, which utilize Ir-192 is more than four times the number of afterloaders for Co-60 [28].

Our prior work asked respondents why they would not switch from Ir-192 and should a more cost-effective isotope be introduced, with the most common answers cited as lack of experience/familiarity, cost, and lack of evidence-based justification. While a priori, one may have expected the introduction of Co-60 to have generated more competition and interest, evaluating the WTPs does perhaps explain its quick entrance and departure from the American market. Nevertheless, the downside of a onetime shielding expense would only apply to those centers who house their afterloaders in a suite conforming only to Ir-192. Previously, we had noted that approximately 70\% of respondents housed their afterloader in a dedicated brachytherapy suite [21] but this work does not apply to settings, in which afterloaders are stored in vaults fitted for older Co-60 teletherapy units or linear accelerators (which produce photons at higher energies). Future work should evaluate physicist WTP as they share the decision-making for many purchasing and acquisition matters, and future work could evaluate the budgetary experiences of other facilities with both Co-60 and Ir-192.

\section{Conclusions}

By comparing the cost of additional shielding for a sample institution's HDR suite with radiation oncolo- gists' WTP, this multi-institutional collaboration noted $<20 \%$ of clinicians would accept additional shielding. Despite low acceptability in the U.S., Co-60 demonstrates cost-favorability in Peru and may similarly in other locales.

\section{Acknowledgements}

This work was supported by an interdepartmental grant sponsored by the Department of Radiation Oncology, Perlmutter Cancer Center, New York University. The authors report no proprietary or commercial interest in any product mentioned or concept discussed in this article.

\section{Disclosure}

Authors report no conflict of interest.

Appendices are published as supplementary data in electronic form on the webpage www.jocb.eu.

\section{References}

1. Danlos H, Bloch P. Note sur le traitement du lupus erythématéux par des applications du radium. Ann Dermatol Syphilog 1901; 2: 986-988.

2. Mould RF. The historical roots of modern brachytherapy for cervical and endometrial cancer. In: Vahrson HW (ed.). Radiation oncology of gynecological cancers. Springer, Berlin, Heidelberg 1997.

3. Myers WG. Applications of artificially radioactive isotopes in therapy: I. Cobalt-60. Am J Roentgenol 1948; 60: 816-823.

4. Williamson JF. Brachytherapy technology and physics practice since 1950: a half-century of progress. Phys Med Biol 2006; 51: R303-325.

5. Horwitz H, Kereiakes JG, Bahr GK et al. An after-loading system utiziling cesium-137 for the treatment of carcinoma of the cervix. Am J Roentgenol Radium Ther Nucl Med 1964; 91: 176-191.

6. Schulz U, Busch M, Bormann U. Interstitial high dose-rate brachytherapy: principle, practice and first clinical experiences with a new remote-controlled afterloading system using Ir-192. Int J Radiat Oncol Biol Phys 1984; 10: 915-920.

7. Grover S, Harkenrider MM, Cho LP et al. Image Guided Cervical Brachytherapy: 2014 Survey of the American Brachytherapy Society. Int J Radiat Oncol Biol Phys 2016; 94 : 598-604. 
8. Harkenrider MM, Grover S, Erickson BA et al. Vaginal brachytherapy for postoperative endometrial cancer: 2014 Survey of the American Brachytherapy Society. Brachytherapy 2016; 15: 23-29.

9. Patel FD, Sharma SC, Negi PS et al. Low dose rate vs. high dose rate brachytherapy in the treatment of carcinoma of the uterine cervix: a clinical trial. Int J Radiat Oncol Biol Phys 1994; 28: 335-341.

10. Hareyama M, Sakata K, Oouchi A et al. High-dose-rate versus low-dose-rate intracavitary therapy for carcinoma of the uterine cervix: a randomized trial. Cancer 2002; 94: 117-124.

11. Lertsanguansinchai P, Lertbutsayanukul C, Shotelersuk K et al. Phase III randomized trial comparing LDR and HDR brachytherapy in treatment of cervical carcinoma. Int J Radiat Oncol Biol Phys 2004; 59: 1424-1431.

12. Aronowitz JN. Afterloading: the technique that rescued brachytherapy. Int J Radiat Oncol Biol Phys 2015; 92: 479-487.

13. O'Connell D, Howard N, Joslin CA et al. A new remotely controlled unit for the treatment of uterine carcinoma. Lancet 1965; 2: 570-571.

14. Papagiannis P, Angelopoulos A, Pantelis E et al. Monte Carlo dosimetry of [sup 60]Co HDR brachytherapy sources. Med Phys 2003; 30: 712-721.

15. Strohmaier S, Zwierzchowski G. Comparison of $60 \mathrm{Co}$ and 192 Ir sources in HDR brachytherapy. J Contemp Brachytherapy 2011; 3: 199-208.

16. Ntekim A, Adenipekun A, Akinlade B et al. High dose rate brachytherapy in the treatment of cervical cancer: Preliminary experience with cobalt 60 radionuclide source-a prospective study. Clin Insights Oncol 2010; 4: 89-94.

17. Zakaria GA, Schütte W, Azhari HA. Dosimetrie an HDR-Afterloading-Geräten mit Ir-192- und Co-60-Strahler: Vergleich verschiedener internationaler Dosimetrieprotokolle. Z Med Phys 2010; 20: 215-224.

18. Ballester F, Granero D, Pérez-Calatayud J et al. Monte Carlo dosimetric study of the BEBIG Co-60 HDR source. Phys Med Biol 2005; 50: N309-N316.

19. Richter J, Baier K, Flentje M. Comparison of 60 Cobalt and 192 Iridium sources in high dose rate afterloading brachytherapy. Strahlenther Onkol 2008; 184: 187-192.

20. Palmer A, Hayman O, Muscat S. Treatment planning study of the 3D dosimetric differences between Co-60 and Ir-192 sources in high dose rate (HDR) brachytherapy for cervix cancer. J Contemp Brachytherapy 2012; 4: 52-59.

21. Mailhot Vega R, Talcott W, Ishaq $O$ et al. A national survey of HDR source knowledge among practicing radiation oncologists and residents: Establishing a willingness-topay threshold for cobalt-60 usage. Brachytherapy 2017; 16: 910-915.

22. National Council on Radiation Protection. NCRP Report \#116, Limitation of Exposure to Ionizing Radiation. Bethesda, MD. 1994

23. Sherer MAS, Visconti PJ, Ritenour ER, Haynes K. Radiation Protection in Medical Radiography. 7th ed. Elsevier Health Sciences, Mosby 2014.

24. National Council on Radiation Protection and Measurements. NCRP Report \#49, Structural Shielding Design and Evaluation for Medical Use of X-Rays and Gamma Rays of Energies up to 10MV. Bethesda, MD. 1976.

25. INEN. 2016 annual metrics of INEN management. http:// www.inen.sld.pe/portal/documentos/pdf/estadistica/datos_estadisticos/01032017_Estadindgest2016.pdf. Published 2017, accessed May 3, 2018.

26. Thaker NG, Pugh TJ, Mahmood U et al. Defining the value framework for prostate brachytherapy using patient-centered outcome metrics and time-driven activity-based costing. Brachytherapy 2016; 15: 274-282.
27. Kaplan RS, Anderson SR. Time-driven activity-based costing. Harv Bus Rev 2004; 82: 131-138, 150.

28. IAEA. DIrectory of RAdiotherapy Centres (DIRAC) [Internet]. NAHU. 1959-present [cited 18 April 2018]. Available from: https:/ / dirac.iaea.org/. 